\title{
Integrated Configuration of Platform Products and Supply Chains for Mass Customization: A Game-Theoretic Approach
}

\author{
George Q. Huang, Xin Yan Zhang, and Victor H. Y. Lo
}

\begin{abstract}
This paper is concerned with optimizing the configuration of a set of platform products and the associated supply chain consisting of one manufacturer and multiple suppliers using a three-move dynamic game-theoretic approach. The variants in the product family share a common platform for developing/configuring variant modules which are substitutable in the sense that high-end module options can functionally replace low-end ones at higher prices. As the customer in the supply chain, the manufacturer takes its leading role by making the first move to give decisions on platform products development (PPD) and supplier selection. The concerned suppliers make the second move to optimize their decisions including price discounts and their ordering policies. The manufacturer finishes the game by taking the last move to make his ordering decisions. The ranges of the rational reactions for the players are derived from the analyses of their payoff models, and an enumerative algorithm is developed to find the subgame perfect equilibrium of the game through the technique of backward induction. The game model and the proposed solution procedure are illustrated through a series of simulation experiments and sensitivity analyses using a numerical example. The results have allowed us to draw some meaningful interpretations and useful managerial insights. The use of platform commonality and modularity has been found generally beneficial not only to the supply chain as a whole but also to individual players that are eventually configured into the game. Flexibility of the suppliers' capability is also found to affect the PPD decisions.
\end{abstract}

Index Terms-Commonality, configuration game, game theory, mass customization, modularity, platform product, supply chain.

\section{INTRODUCTION}

M ASS customization, the concept which aims at providing a high level of product variety that best serves a segmented market in a timely manner and at a reasonably low cost [1], has received extensive attention since its emergence. Among the many strategies of mitigating the cost concerns of product customization is that of platform products development (PPD) based on the concept of platforming. Here, it is necessary to define the terms variant module, common module, and

Manuscript received November 7, 2004; revised April 12, 2005. Review of this manuscript was arranged by Special Issue Department Editor T. Blecker. This work was supported in part by The University of Hong Kong Research Committee. The work of G. Q. Huang was supported in part by the National Science Foundation of China (NSFC) under Grant 70629002 the University of Hong Kong Research Committee and Outstanding (Overseas) Young Scholar Award.

The authors are with the Department of Industrial and Manufacturing Systems Engineering, The University of Hong Kong, Hong Kong (e-mail: gqhuang@hku.hk6; zhang-xin-yan@hkusua.hku.hk; vhylo@hku.hk).

Color versions of Figs. 5-8 are available online at http://ieeexplore.ieee.org. Digital Object Identifier 10.1109/TEM.2006.889074 module option used in this paper. Just like the concept of platform, modular product architecture is also widely introduced under the circumstance of mass customization, since it increases flexibility and decreases cycle time in design and manufacturing [2]. Under the modular product architecture, platform products normally have a fixed number of modules. Each module in turn may have several module options which are somewhat different from each other. The module which has only one module option is a common module and the module which has more than one module options is a variant module. Customization can be achieved through allowing variant modules to choose among a set of given module options. The notion of the variant module here is similar to that of "module type" proposed by Chakravarty and Balakrishnan [3] and that of "replaceable component set" introduced by Gupta and Krishnan [4]. Similar to their work, we also assume that module options of a variant module can be arranged in some order of a certain performance characteristic.

In this context, customer requirements and end-products can be specified by the module options preferred or assigned. The concept of platforming in this paper means using a module option with higher performance level in stead of that which is preferred by customers to achieve platform commonality among each variant of the platform products. In this way, PPD can be regarded as a trade-off between providing each market segment with a product exactly satisfying its requirements and economies of scale achieved by platforming.

On the other hand, in order to achieve quick response required by mass customization, manufacturers are facing an increasing need to extend the scope of their development process to include the considerations about their supply chains. The emerging theme, integrated configuration of platform products and supply chain (ICPPSC), has been investigated by some researchers [3], [4], and [6] in terms of that all the design decisions of the end-products and the associated supply chain are made by the manufacturer unilaterally. In this paper, we investigate the ICPPSC problem of a supply chain consisting of a single manufacturer and multiple suppliers. The Manufacturer is responsible for developing and producing a set of platform products to meet the customer requirements and the suppliers are responsible for producing and supplying module options required by the Manufacturer. It is assumed that the product platform and its architecture as represented by generic bill-of-material (GBOM) have been established. It is also assumed that there is some kind of knowledge sharing between the Manufacturer and the suppliers, but not between individual suppliers. 
We investigate this ICPPSC problem through a game-theoretic framework. In this paper, we describe the ICPPSC game as a dynamic multistage noncooperative configuration game. In this game, the Manufacturer is treated as the leader and suppliers as followers. They are both rational players in the game. The decision variables to be optimized are mainly concerned with product and supply chain configuration, including supplier selection and selection of module options, etc. For this reason, this game is called a configuration game. A configuration is very special when compared with those inventory games [7], [8] and scheduling games [9], [10] seen in the supply chain literature. In these games, supply selection is not a decision variable and selected suppliers are treated as game players. However, in a configuration game where supplier selection is a typical variable, whether or not alternative suppliers should be treated as players is an important issue, causing a lot of technical difficulties in solving the game equilibriums.

Our main objective in this paper is to build a synergy between PPD and SCC decisions through a game-theoretic approach, and then to explore how design decisions of platform products and supply chain affect each other. Based on the game structure, we are particularly interested in the following questions: 1) How does the platforming strategy affect the optimal configuration decisions of the Manufacturer and the suppliers? 2) How does the platforming strategy affect the objectives of the Manufacturer and the suppliers? 3) How is the platforming strategy affected by the supply chain decisions such as suppliers' decisions on their flexibilities? 4) How do the supply chain parameters such as the total demand volume affect the platforming strategy, as well as the findings observed from the above questions? These research questions will be addressed by solving our configuration game of ICPPSC problem under various scenarios constructed by varying key parameters.

The remainder of the paper is organized as follows. Section II presents a review for literature related to ICPPSC problem and supplier-manufacturer relationship adopting game-theoretic approaches. We then describe our research problem through an illustrative example and the framework of the ICPPSC game in Section III while the game is mathematically defined in Section IV. Section V proposes a global search algorithm by deriving properties from the model to solve the ICPPSC game. Section VI applies the resulting game model and solution algorithm to study a simple illustrative case and a series of simulation studies are conducted to gain some useful insights. The paper concludes with a wrap-up discussion and some directions for future research.

\section{LITERATURE REVIEW}

The two areas, supply chain configuration and product line and family design for mass customization, have been separately studied on their own. Although it is widely acknowledged that these two areas are closely interrelated with each, they have rarely been studied in an, integrated, systematic and comprehensive manner. This is evident from a recent special issue on the topic [11]. In addition, Game Theory (GT) has also been applied to study supply chain management (SCM) problems. However, GT has not yet found its application in solving SCC problems, almost certainly not for the ICPPSC problem. This section will briefly highlight a few representative works somewhat related to this research.

\section{A. Product Line/Family Design and Supply Chain Configuration}

Various models have been devised for extending and designing the product line instead of a single product to overcome the cost concerns of increased product variety, as reviewed by Yano and Dobson [12]. Thonemann and Bradley [13] investigated the impact of product variety on supply chain performance. Kohli and Sukumar [14] formulated a joint problem of designing a set of candidate products to maximize the manufacturer's profit margin. Morgan et al. [15] indicated that the product line design problem has typically been discussed from a marketing perspective, focusing on how alternative sets of products interact and compete in the marketplace. Raman and Chhajed [16] formulated a more complicated problem of choosing products and appropriate manufacturing processes, and setting product prices.

Shared common components, product structure and manufacturing assets by a product family or line are often defined as its platform [17], [18]. The positive impacts of platform (component) commonality have been widely demonstrated with respect to component demand patterns, work-center load, work-in-progress inventory, and delivery performance [19], [20]. Platform commonality has led to simplified planning and scheduling [22], lower setup and holding costs [20], [21], lower safety stock [23], [24], reduction of vendor lead time uncertainty [25]), and order quantity economies [26], [27]).

Ramdas and Sawhney [28] presented a cross-functional approach to evaluating multiple line extensions that simultaneously considers revenue implications of component sharing at the product level and cost implications at the component level. Kim et al. [29] developed a mathematical model and a solution algorithm for assisting the manufacturer to configure its supply chain for a mix of multiple products sharing some common raw materials and/or component parts. Gupta and Krishnan [4] and Krishnan and Gupta [5] presented a decision support methodology for identifying and formalizing tradeoffs between development costs and benefits of product platforms. Chakravarty and Balakrishnan [3] developed a mathematical model for investigating the tradeoffs in product design between manufacturing and development costs and the potential market value.

Literature comprehensively and systematically dealing with product platform strategies and SCM, however, is limited. Salvador et al. [30] and Park [6] are among the very few. The former is based on empirical data while the latter uses simulation with a very complicated model.

\section{B. GT for Solving SCM Problems}

Cachon and Netessine [31] gave a comprehensive overview and general appealing features of applying GT to study SCM problems. The newsvendor problem (selling product with short lifecycle to customers) had been widely used [32], [33]. Bakos and Brynjolfsson [34] constructed a game model for a comprehensive study of the optimal number of suppliers for a buyer. Rhim [35] formulated a supply chain design problem as a three- 


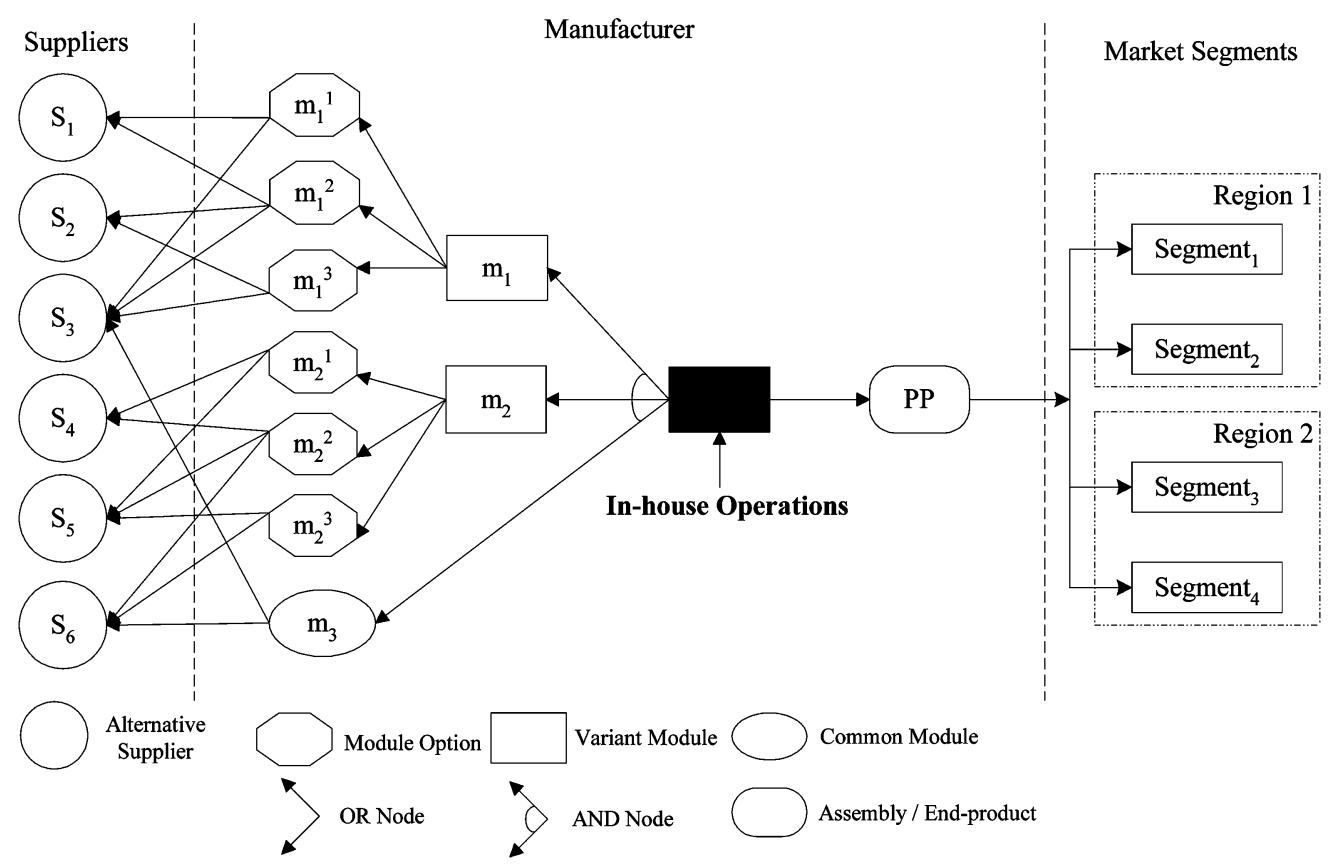

Fig. 1. Integrated PPD and supply chain configuration.

stage noncooperative game covering location, capacity, and production quantity. Talluri and Baker [36] considered a threelevel supply chain of suppliers, manufacturers and distributors and developed a hybrid mathematical programming approach to solving the game. Moyaux [37] applied a normal form game to model a supply chain and analyzed the information sharing and bullwhip effect.

The supplier-manufacturer or vendor-buyer relationship problem of SCM, especially the quantity discount problem has been extensively examined using GT [38], [39], [40], [41], [42]. Among them, Lal and Staelin [38], Wang [41], and Rosenblatt and Lee [39] address the problem of how a supplier should design his discount pricing policy to maximize his payoff while still making the buyer(s) better off. Parlar and Wang [40] and Viswanathan and Wang [42] model their discount pricing problem as the Stackelberg game in which the supplier acts as the leader and the manufacturer(s) act as the follower(s). Parlar and Wang [40] show that both the vendor and the buyers can benefit from the quantity discount policy. Viswanathan and Wang [42] evaluate the impacts of quantity discount and volume discount on the distribution channel, respectively, and simultaneously and find out that quantity discount has higher impacts when the demand is less price-sensitive while the volume discount has higher impacts when the demand is more price-sensitive.

In addition to this type of quantity discount games, inventory games have also been widely studied in SCM [7]. In contrast with inventory games and quantity discount games, GT applications to SCC have been very limited. Smirnov [43] formulated the SCC problem as a coalition game which is solved by a combination of soft-computing techniques. Zhang [44] considered a complex supply chain network involving multiple suppliers, manufacturers, retailers and demand markets. However, the variables considered in the network model do not cover configuration design of products, processes, resources, supply sources. Because supplier selection is a typical variable, whether or not suppliers should be treated as players is an issue when SCC is formulated as a game.

\section{Problem Statement And Notations}

\section{A. Description of the Problem and Some Notations With an Illustrative Example}

We consider a Manufacturer facing the customer demands of market segment indicated by the subscript $i=1,2, \ldots, I$ and each market segment has a threshold requirement. End-products produced by the Manufacturer are split into a set of modules including variant modules indicated by the subscript $j=1,2, \ldots, J$. Each variant module $j$ can have many module options that could be interchanged to provide the desired performance levels, and are indicated by the superscript $k=1,2, \ldots, K_{j}$, as can be seen schematically in Fig. 1 .

The illustrative platform products (PP) in Fig. 1 are composed of three modules. Although it is schematic, for example in the context of computer design, one can think of $m_{1}$ as being CPU, $m_{2}$ as a hard disk module, and $m_{3}$ as the motherboard. These modules are designed and connected by the Manufacturer through a fixed number of assembly processes. Among these modules, $m_{3}$ is a common module as it is common to each variant in the product family. The two variant modules, $m_{1}$ and $m_{2}$, each of them has three module options. Here we give the first important assumption of this paper, which has been mentioned in Section I.

Assumption 1: Module options of each variant module can be arranged in an increasing order of a certain performance characteristic. 
The Manufacturer in Fig. 1 aims its product family at two market regions, each of which has two market segments. Therefore, there are four market segments should be served. With respect to customer requirements, we assume the following.

Assumption 2: The primary requirement of the customers in each market segment can be represented by the module options of each variant module, and it is only allowed to configure a product that offers higher ordered module options than the customer's requirements.

We define the primary requirement matrix, $\mathbf{R}$, such that

$$
\mathbf{R}_{j, i}=k
$$

where $k$ is the primary module option of variant module $j$ required by the customers in market segment $i$. Also, we define the PPD decision matrix of the Manufacturer, $\mathbf{M}$, to represent the mix of module options eventually used in the platform products by the Manufacturer, such that

$$
M_{j, i}=k .
$$

The selected module options are assembled by the Manufacturer into assemblies and then end-products which are then delivered by the Manufacturer to the market segments. Let the Manufacturer's estimate of the lifecycle demand at each market segment be $d_{i}(i=1, \ldots, I)$, then the total market demand for the product family, $D$, is $\sum_{i=1}^{I} d_{i}$. With respect to $d_{i}$, we assume the following.

Assumption 3: The forecasted demand of a market segment is not affected by the actual PPD decision of the Manufacturer.

All the module options needed are purchased from a fixed number of alternative suppliers $s=1,2, \ldots, S$. For the platform products in Fig. 1, there are 6 alternative suppliers. For simplicity and without losing generality, we assume that each supplier $s$ can only produce one kind of variant module, namely $j^{s}$, and his capability or flexibility is measured by the number of module options it can supply. Specifically, we consider two kinds of suppliers according to their flexibility levels: high and low. The supplier with high flexibility can supply all the module options of a variant module. The supplier with low flexibility can only supply either the lower half or the higher half of module options of a variant module. In the example shown in Fig. $1, S_{3}$ and $S_{6}$ are suppliers with high flexibility, while $S_{1}, S_{2}, S_{4}$, and $S_{5}$ are suppliers with low flexibility. In this paper, we assume the following.

Assumption 4: The capacity of each supplier is unlimited, and using single sourcing strategy for each used module option is optimal for the Manufacturer.

We define the supplier selection matrix $\mathbf{Y}$ to represent the decision result of supplier selection of the Manufacturer, such that

$$
\mathbf{Y}_{j, k}=s
$$

where $s \in S_{k}$ and is the selected supplier to supply the module option $k$ of module $j$, and the ordering decision vector $\mathbf{T}=$ $\left(T_{1}, \ldots T_{s}, \ldots, T_{S}\right)$ where $T_{s}$ is the Manufacturer's decision of ordering cycles to supplier $s$.

\section{B. Description of the Game Scheme}

In the kind of supply chain shown in Fig. 1, the Manufacturer is the driving customer of the suppliers and, therefore, holds a more powerful position in making decisions related to product configuration and supplier selection. Therefore, the Manufacturer acts as the leader to make decisions on PPD (e.g., which module option should be used) and supplier selection decisions (e.g., which supplier should rely on for each selected module option). Each supplier, if selected, in turn faces demands from the Manufacturer, and acts independently to make its pricing and ordering decisions. In other words, it is the Manufacturer who makes the PPD decision in this game. Once the PPD decision is given, the Manufacturer and suppliers make the SCC decisions jointly. It is clear that the SCC decisions here include supplier selection, pricing, and ordering decisions within the entire supply chain.

We describe the ICPPSC problem in this paper as a threemove noncooperative configuration game with $S+1$ players, i.e., one Manufacturer and $S$ suppliers. Each supplier controls decision vectors set $X_{s}(s=1, \ldots, S)$ to maximize his pay-off function $f_{s}$, and the Manufacturer controls the decision vectors sets $X_{S+1}^{1}$ and $X_{S+1}^{2}$ to maximize his pay-off function $f_{S+1}$.

In our game framework, the Manufacturer makes the first and the third moves. In his first move, a decision vector $x_{S+1}^{1} \in$ $X_{S+1}^{1}$ includes PPD and supplier selection decisions is given. From this decision vector, the total demand of module options awarded to each supplier can be derived and be transferred to them. After the suppliers give their rational reactions, the Manufacturer moves again to give a decision vector $x_{S+1}^{2} \in X_{S+1}^{2}$ includes his ordering decisions to each selected supplier. When the Manufacturer makes his PPD decision, using higher performance module options in place of lower performance module options may cost him more in purchasing. However, this can creates scale economies in module option designing, inventory, and ordering costs.

A decision vector $x_{s} \in X_{s}$ of supplier $s$ includes ordering decisions and discounted pricing decisions. The aim of suppliers is maximize their pay-off functions $f_{s}(s=1, \ldots, S)$ by selling module options to the Manufacturer. In fact, the Manufacturer can not make his ordering decisions until the suppliers offer their quantity discount schedules.

The sequential decision structure of the three-move noncooperative configuration game is shown in Fig. 2. It is clear that the Manufacturer holds more powerful position in the sequential decision process in which he can impose decisions upon the suppliers. However, suppliers can also affect some of the Manufacturer's decisions in their turn.

\section{MOdEL FoRMULATION}

\section{A. The Manufacturer's Model}

According to the Assumption 2, which implies that the Manufacturer will not charge more from the customers even if he offers platform products with higher performance than the customers' primary requirements, and the Assumption 3, we can get that the total revenue of the Manufacturer is not affected by his PPD decision. In this case, maximizing total profit equals to minimizing the total cost of the Manufacturer. Therefore, the objective function of the Manufacturer is to minimize the total cost associated with developing, procuring, 
TABLE I

PARAMETERS AND VARIABLES OF THE MANUFACTURER

\begin{tabular}{cl}
\hline Symbol & \multicolumn{1}{c}{ Meaning } \\
\hline$v_{j k}$ & binary decision variable to indicate whether module option $k$ is used by the Manufacturer \\
$w_{s}$ & binary decision variable to indicate whether supplier $s$ has been used. \\
$y_{j k s}$ & binary decision variable to indicate whether supplier $s$ has been selected to supply module option $k$. \\
$x_{i j k}$ & binary decision variable indicating whether module option $k$ is used in market segment $i$. \\
$U_{s}$ & total unit of module options purchased from the capable supplier $s$. \\
$h$ & holding cost rate per unit per year. \\
$D C_{j k}$ & a fixed cost of designing, prototyping, and testing module option $k$. \\
$A$ & ordering cost occurs at each order placed by the Manufacturer. \\
$p_{j k s}$ & unit selling price for module option $k$ purchased from supplier $s$. \\
$u_{j k}$ & the lifecycle demand rate for module option $k$ according to the actual PPD decision.
\end{tabular}

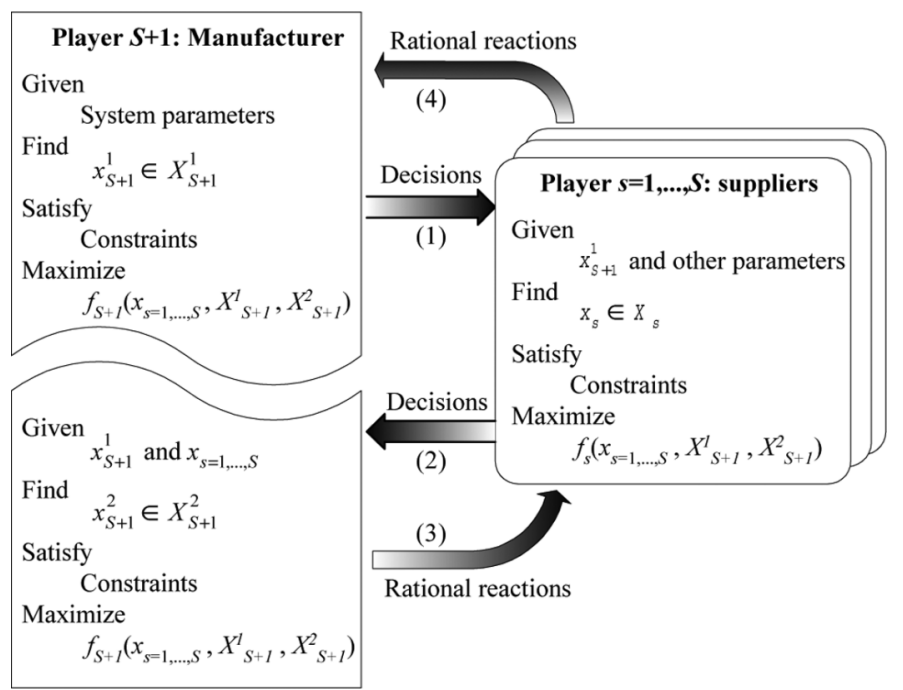

Fig. 2. Sequential decision structure of the ICPPSC configuration game.

ordering, and inventory of module options that make up the platform products, while meeting the customer requirements. When choosing module options and suppliers for the platform products, the Manufacturer incurs two different costs, namely development cost $(D C)$, and souring cost $(S C)$. Once the configuration of the platform products, or PPD decision matrix $\mathbf{M}$, is decided, $D C$ becomes a fixed cost based on the selected module options. In other words, $D C$ is decided by the Manufacturer's PPD decisions. $S C$, on the other hand, is a variable cost affected by the Manufacturer's SCC decisions. The relevant parameters and variables of the Manufacturer are designed in Table I.

Note that $x_{i j k}, v_{j k}, y_{j k s}$, and $w_{s}$ can be viewed as decision variables too because they are deduced from the two decision matrices, PPD decision matrix, $\mathbf{M}$, and supplier selection matrix, Y. Then the objective function of the Manufacturer under the planning horizon is as follows:

$$
\begin{aligned}
\operatorname{Min} C_{M}(\mathbf{M}, \mathbf{Y}, \mathbf{T})= & \sum_{j=1}^{J} \sum_{k=1}^{K_{j}} D C_{j k} v_{j k} \\
& +\sum_{s=1}^{S} w_{s}\left[\sum_{j=j^{s}}^{j^{s}} \sum_{k=1}^{K_{j}} u_{j k} y_{j k s} p_{j k s}\right. \\
& \left.+A T_{s}+\frac{h U_{s}}{2 T_{s}}\right]
\end{aligned}
$$

subject to

$$
\begin{aligned}
\mathbf{M}_{j, i} & \geq \mathbf{R}_{j, i} \text { for } i=1,2, \ldots, I \\
j & =1,2, \ldots, J \\
x_{i j k} & = \begin{cases}1, & \text { if } \mathbf{M}_{j, i}=k \\
0, & \text { otherwise }\end{cases} \\
u_{j k} & =\sum_{i=1}^{I} d_{i} x_{i j k}, \\
v_{j k} & = \begin{cases}1, & \text { if } u_{j k}>0 \\
0, & \text { otherwise }\end{cases} \\
y_{j k s} & = \begin{cases}1, & \text { if } \mathbf{Y}_{j, k}=s \\
0, & \text { otherwise }\end{cases} \\
w_{s} & = \begin{cases}1, & \text { if } \sum_{j=j^{s}}^{j^{s}} \sum_{k=1}^{K} y_{j k s} \geq 1 \\
0, & \text { otherwise }\end{cases} \\
U_{s} & =\sum_{j=j^{s}}^{\sum_{k=1}^{K_{j}} u_{j k} y_{j k s}} \\
T_{s} \geq 1 \text { and integer. } &
\end{aligned}
$$

Basically, the minimization of the total cost by the manufacturer is equivalent to the maximization of its profit, because the total revenue generated from the customer orders for the final products is a fixed constant in this study.

Constraint (2) ensures the Assumption 1 of one-way substitution between module options. Constraints (3) to (5) set the values of $x_{i j k}, u_{j k}, v_{j k}, y_{j k s}, w_{s}$, and $U_{s}$. Constraint (6) ensures that $T_{s}$ is a positive integer.

The first term of the above objective function, $D C$, is relatively simple. Once the configuration of the product family, or matrix $\mathbf{M}$, is decided, $D C$ can be calculated easily. The second term of the above objective function, $S C$, is clearly composed of three parts. The first part is total unit purchase cost (PurC) paid to suppliers, the second one is ordering cost $(\mathrm{OrdC})$, and the last one is raw material inventory holding cost (InvC). Since $D C$ becomes constant once the Manufacturer's PPD decision is given, the Manufacturer's objective function after he made his PPD decision is $S C(\mathbf{Y}, \mathbf{T})$

$$
\begin{aligned}
S C(\mathbf{Y}, \mathbf{T}) & =\operatorname{PurC}+\operatorname{OrdC}+\operatorname{Inv} C \\
& =\sum_{s=1}^{S} w_{s}\left[\sum_{j=j^{s}}^{j^{s}} \sum_{k=1}^{K_{j}} u_{j k} y_{j k s} p_{j k s}+A T_{s}+\frac{h U_{s}}{2 T_{s}}\right] .
\end{aligned}
$$


TABLE II

PARAMETERS AND VARIABLES OF SUPPLIERS

\begin{tabular}{cl}
\hline Symbol & \multicolumn{1}{c}{ Meaning } \\
\hline$p_{j k s}^{0}$ & undiscounted unit selling price for module option $k$ \\
$A_{s}$ & order processing cost \\
$F_{s k}$ & manufacturing set up cost for module option $k$ at supplier $s$ \\
$c_{j k s}$ & unit production cost of module option $k$ \\
$V_{s}$ & ordering cost occurs at each order placed by $s$ with his supplier \\
$h_{s}$ & holding cost rate per unit per year \\
$I_{s}$ & decision variable, $s$ 's ordering cycles \\
$b_{s}$ & decision variable, discount rate \\
$p_{j k s}$ & discounted unit selling price for module option $k$, where $p_{j k s}=p_{j k s}^{0}-b_{s}\left(U_{s} / T_{s}\right)$. \\
\hline
\end{tabular}

For each supplier $s=1,2, \ldots, S$, if he is selected, the relevant sourcing cost of the Manufacturer incurred by the procurement of module options from this supplier; namely, $S C_{s}\left(T_{s}\right)$, can be represented by

$$
\begin{aligned}
S C_{s}\left(T_{s}\right) & =\operatorname{PurC}_{s}+\operatorname{Ord} C_{s}+\operatorname{Inv} C_{s} \\
& =\sum_{j=j^{s}}^{j^{s}} \sum_{k=1}^{K_{j}} u_{j k} y_{j k s} p_{j k s}+A T_{s}+\frac{h U_{s}}{2 T_{s}} .
\end{aligned}
$$

Therefore, we have $S C=\sum_{s=1}^{S} w_{s} S C_{s}$.

\section{B. Suppliers' Model}

For simplicity of modeling and representation, we assume that each supplier is homogenous with respect to the production of module options. That is, for each supplier, the objective is to maximize its total profit, $\pi_{s}$, from the sales of module options to the Manufacturer, which is equivalent to the total revenue minus order processing cost, manufacturing setup cost, raw material ordering cost and inventory holding cost. The relevant parameters and variables of any supplier $s=1, \ldots, S$ are given by Table II.

Given the ordering cycles of the manufacturer, $T_{s}$, to supplier $s$, it can be easily shown that the supplier $s$ 's ordering cycles $I_{s}$ should be some integer division of $T_{s}$. Let $I_{s}=T_{s} / \theta_{s}$, where $\theta_{s}$ is an integer, and $\theta_{s} \geq 1$. Since $U_{s} / T_{s}$ units are delivered to the manufacturer as soon as the supplier $s$ 's raw material inventory is replenished, the average raw material inventory held by the supplier $s$ will be $\left(\theta_{s}-1\right) U_{s} / 2 T_{s}$ [45], [42]. Thus, the supplier $s$ 's objective function is as follows:

$$
\begin{array}{rl}
\operatorname{Max} & \pi_{s}\left(b_{s}, \theta_{s}\right) \\
= & \sum_{j=j^{s}}^{j^{s}} \sum_{k=1}^{K_{j}} u_{j k} y_{j k s}\left(p_{j k s}-c_{j k s}\right) \\
& -\left(A_{s}+F_{s}\right) T_{s}-\frac{V_{s} T_{s}}{\theta_{s}}-\frac{h_{s}\left(\theta_{s}-1\right) U_{s}}{2 T_{s}} \\
F_{s}= & \sum_{j=j^{s}}^{j^{s}} \sum_{k=1}^{K_{j}} F_{k} y_{j k s} \\
p_{j k s}= & p_{j k s}^{0}-b_{s}\left(\frac{U_{s}}{T_{s}}\right) \\
b_{s} \geq 0 & 0
\end{array}
$$

$$
\begin{aligned}
& p_{j k s}^{0}-b_{s}\left(\frac{U_{s}}{T_{s}}\right) \geq c_{j k s}+\varepsilon_{j k s} \\
& \quad \text { for each } k=1,2, \ldots, K_{j^{s}} \\
& \theta_{s} \geq 1 \text { and integer }
\end{aligned}
$$

Constraint (10) gives the value of $F_{s}$ which represents the total manufacturing set up cost occurs at supplier $s$. Constraint (12) ensures that the value of $b_{s}$ is nonnegative since the unit price of module option is given by (11). Constraint (13) ensures that the unit price offered by any supplier is not lower than the unit manufacturing cost of the module option where $\varepsilon_{j k s}$ is unit profit margin desired by the supplier. Constraint (14) ensures that $\theta_{s}$ is a positive integer.

\section{Game-Theoretic Model}

Without sufficient communication between the Manufacturer and the suppliers, it is the Manufacturer who holds a comparatively powerful position over the suppliers because the Manufacturer acts first to offer PPD and supplier selection decisions to the suppliers. Based on the decision structure of the game shown in Fig. 2 and the above objective functions of all the players, we can formulate the three-move dynamic configuration game as follows:

\section{$\operatorname{Min} C_{M}(\mathbf{M}, \mathbf{Y})$}

subject to

constraints (2)-(5)

$\operatorname{Max} \pi_{s}\left(b_{s}, \theta_{s}\right)$, for each $s=1,2, \ldots, S$ and $w_{s}=1$

subject to

constraints (10)-(14)

$\operatorname{Min} S C_{s}\left(T_{s}\right)$

subject to:

Constraint (6).

Before continuing the analysis, let us again consider the assumption that all suppliers are homogeneous and, therefore, have the same cost structure. This assumption is technically not necessary for developing the model and solution technique. Instead, it is only introduced for convenience of representation and analysis. In other words, we only need one uniform formula to represent the objective function (payoff) $\pi_{s}$ of each supplier 
(player) as defined in (9)-(14) and constraints $\operatorname{Max}_{s}\left(b_{s}, \theta_{s}\right)$, for each $s=1,2, \ldots, S$ and $w_{s}=1$ in the game model. It is, however, perfectly appropriate for suppliers to have different forms of cost (profit) structures. In this case, these equations and constraints must be worked out and represented separately. Appropriate solution techniques should also be considered for each cost function of each supplier.

\section{Model Analysis}

In this section, we derive some optimization conditions for the above game model. First we consider when no quantity discount schedules are offered by the suppliers. In this case, we have $p_{j k s}=p_{j k s}^{0}$ and the optimal decision on ordering cycles to each selected supplier $s, T_{s}$, of the Manufacturer to minimize $S C_{s}\left(T_{s}\right)$ can be obtained following the classical Economic Order Quantity (EOQ) policy from (8). Thus, we have

$$
T_{s}^{*}=\sqrt{\frac{h U_{s}}{2 A}} .
$$

Now, suppose that $p_{j k s}$ and $T_{s}$ for any selected supplier $s$ are fixed, then the supplier $s$ 's problem of finding the optimal ordering cycles, $I_{s}=T_{s} / \theta_{s}$ in this case becomes

$$
\min _{\substack{\theta_{s} \geq 1 \\ \theta_{s}=\text { int }}} \delta_{s}=\frac{V_{s} T_{s}}{\theta_{s}}+\frac{h_{s}\left(\theta_{s}-1\right) U_{s}}{2 T_{s}} .
$$

The value of $\theta_{s}$ that minimizes $\delta_{s}$ is given by the smallest $\theta_{s}^{*}$ that satisfies (see [39])

$$
\theta_{s}^{*}\left(\theta_{s}^{*}-1\right) \leq \frac{2 V_{s} T_{s}^{2}}{h_{s} U_{s}} \leq \theta_{s}^{*}\left(\theta_{s}^{*}+1\right) .
$$

Let us define $\lfloor a\rfloor$ as the largest integer no lager than $a$. One calculation method for $\theta_{s}^{*}$ can be expressed as follows (see [42]):

$$
\theta_{s}^{*}=\left\lfloor\frac{\left(1+\sqrt{1+\left(\frac{8 V_{s} T_{s}^{2}}{h_{s} U_{s}}\right)}\right)}{2}\right\rfloor .
$$

Now let us consider the condition when all the suppliers are offering the following linear quantity discount schedule: $p_{j k s}=$ $p_{j k s}^{0}-b_{s}\left(U_{s} / T_{s}\right)$, where $U_{s} / T_{s}$ is the Manufacturer's ordering quantity to supplier $s$. Substituting for $p_{j k s}$ from (11) into (8), we get the Manufacturer's objective function in this case as follows:

$$
S C_{s}\left(T_{s}\right)=\sum_{j=j^{s}}^{j^{s}} \sum_{k=1}^{K_{j}} u_{j k} x_{j k s}\left[p_{j k s}^{0}-b_{s}\left(\frac{U_{s}}{T_{s}}\right)\right]
$$

The necessary condition for the minimum of $S C_{s}$ is

or

$$
\frac{d S C_{s}\left(T_{s}\right)}{d T_{s}}=\frac{b_{s} U_{s}^{2}}{T_{s}^{2}}+A-\frac{h U_{s}}{2 T_{s}^{2}}=0
$$

$$
b_{s}=\frac{\left(\frac{h U_{s}}{2}\right)-\left(A T_{s}^{2}\right)}{U_{s}^{2}} .
$$

Using the above equation, the Manufacturer can find his optimal decision of $T_{s}$ to each supplier $s$ once the value of $b_{s}$ is given. Substituting (17) into constraint (12), we get

$$
\left(\frac{h U_{s}}{2}\right)-\left(A T_{s}^{2}\right) \geq 0
$$

or

$$
T_{s} \leq \sqrt{\frac{h U_{s}}{2 A}}=T_{s}^{*} .
$$

Substituting (18) into constraint (13) and using $\Delta_{j k s}$ for $p_{j k s}^{0}-c_{j k s}-\varepsilon_{j k s}$, for each module option $k=1,2, \ldots, K_{j}$ of module $j^{s}$ where $u_{j k}>0$ and is purchased from supplier $s$, i.e., $y_{j k s}=1$, we can get

$$
\Delta_{j k s} \geq b_{s}\left(\frac{U_{s}}{T_{s}}\right)=\frac{h}{2 T_{a}}-\frac{A T_{s}}{U_{s}}
$$

or

$$
\begin{aligned}
& T_{s}^{2}+\frac{\Delta_{j k s} U_{s}}{A} T_{s}-\frac{h U_{s}}{2 A} \geq 0 \\
& \quad \text { for } k=1,2, \ldots, K_{j}, \quad x_{j k s}=1, \\
& \quad u_{j k}>0, \quad j=j^{s} .
\end{aligned}
$$

Define

$$
T_{s}^{\prime}=-\frac{\Delta_{j k s} U_{s}}{2 A}+\sqrt{\frac{\Delta_{j k s}^{2} U_{s}^{2}}{4 A^{2}}+\frac{h U_{s}}{2 A}}
$$

and

$$
\begin{gathered}
T_{s}^{\prime \prime}=\max \left\{T_{s}^{\prime} \mid k=1,2, \ldots, K_{j}, y_{j k s}=1,\right. \\
\left.u_{j k}>0, j=j^{s}\right\} .
\end{gathered}
$$

Then, (20) is equivalent to

$$
T_{s} \geq T_{s}^{\prime \prime}
$$

When supplier $s$ is not selected for supplying module option $k$, i.e., $y_{j k s}=0$, or the module option is not used by the Manufacturer at all, i.e., $u_{j k}=0$, constraint (13) becomes $p_{j k s}^{0} \geq c_{j k s}+\varepsilon_{j k s}$ and can be ensured by system inputs.

Combining (6), (19), and (22), the reaction range of the Manufacturer's decision variable, $T_{s}$, that needs to be considered during his second or system's third move is given by

$$
\max \left\{1, T_{s}^{\prime \prime}\right\} \leq T_{s} \leq T_{s}^{*}, T_{s} \text { is integer. }
$$

Furthermore, recall that once the value of $T_{s}$ is given, the optimal value of $\theta_{s}^{*}$ can be obtained from (17). Define the lower 


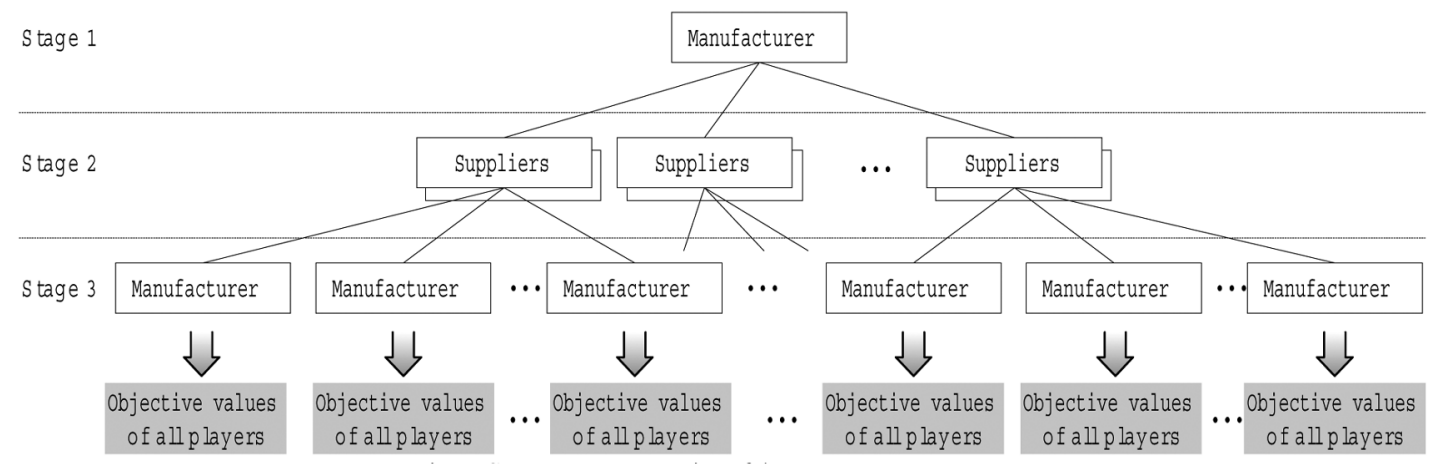

Fig. 3. Game tree representation of the game.

and higher bounds of $\theta_{s}^{*}$ to be $\underline{\theta_{s}^{*}}$ and $\overline{\theta_{s}^{*}}$, respectively. Then, we have

$$
\underline{\theta_{s}^{*}}=\left\lfloor\frac{\left(1+\sqrt{1+\left(\frac{8 V_{s}\left(\max \left\{1, T_{s}\right\}\right)^{2}}{h_{s} U_{s}}\right)}\right)}{2}\right\rfloor
$$

and

$$
\overline{\theta_{s}^{*}}=\left\lfloor\frac{\left(1+\sqrt{1+\left(\frac{8 V_{s}\left(T_{s}^{*}\right)^{2}}{h_{s} U_{s}}\right)}\right)}{2}\right\rfloor .
$$

Rearranging (16) we get range of the values of $T_{s}$. Hence

$$
\left\lceil\sqrt{\frac{h_{s} U_{s}}{2 V_{s}} \theta_{s}^{*}\left(\theta_{s}^{*}-1\right)}\right\rfloor \leq T_{s} \leq\left\lfloor\sqrt{\frac{h_{s} U_{s}}{2 V_{s}} \theta_{s}^{*}\left(\theta_{s}^{*}+1\right)}\right\rfloor .
$$

We define $\lceil a\rceil$ as the smallest integer no smaller than $\alpha$.

\section{E. Solution Procedure}

For noncooperative static games, Nash equilibrium is widely known as the solution point at which every player has no reason to change his behavior. In our noncooperative three-stage dynamic game of complete and perfect information, we apply the extended solution concept of subgame perfect equilibrium to analyze the strategic behaviors of the players, i.e., the Manufacturer and suppliers. We construct the complete extensive form of our game which is illustrated in Fig. 3.

We assume that the Manufacturer has a finite number of platform products configuration decisions, or PPD decision matrices, $\mathbf{M}$, which are indicated by the superscript $n$, where $n=$ $1,2, \ldots, N$, and a finite number of supplier selection decisions, or supplier selection matrices, $\mathbf{Y}$, which are indicated by the superscript $f$, where $f=1,2, \ldots, F$. Then the number of possible strategies of the Manufacturer at stage 1 is $N \times F$. Thus, there are $N \times F$ subgames at stage 2, one beginning at each of Suppliers' decision nodes. The inputs of each subgame are the Manufacturer's decisions, $\mathbf{M}^{n}$ and $\mathbf{Y}^{f}$.

In this paper, we propose a solution procedure based on the technique of backward induction which can be used to find a subgame perfect equilibrium. Once strategies are assigned at each stage, we can calculate the corresponding objective value for each player. Then, we can determine a subgame perfect equilibrium according to each player's objective using backward induction. The solution algorithm is briefly summarized in Fig. 4 . The right half of Fig. 4 is the solution procedure of subgames.

\section{NumERICAL EXAMPLE AND SENSITIVITY ANALYSIS}

In this section, we present a simple numerical example to demonstrate the applicability of the proposed solution framework to our game problem. Through this example, we are also interested in investigating the mutual impacts between PPD decisions and SCC decisions.

\section{A. Initialization of Model Parameters}

We aim to construct a product family which retails at approximately $\$ 1,500$, which has two variant modules $\left(m_{1}\right.$ and $\left.m_{2}\right)$ in its GBOM. Each of the two variant modules has 4 module options. The relative values of $m_{1}$ and $m_{2}$ to the total value of an entire product are approximately at $18.3 \%$ and $9.3 \%$, respectively.

The product family serves 2 market regions, namely Europe (EU) and North America (NA), and each regional market has 4 market segments. Thus, there are totally 8 market segments. It is reasonable that each market region has a different market size. Thus, we assume that EU and NA have approximately $45 \%$ and $55 \%$ of the given worldwide demand volume $(D)$, respectively. Demand volume for each market segment is equal to the average demand volume of the market segments of the region. With respect to primary requirements of market segments, we assume that EU prefers lower-end module options while UA prefers higher-end module options. The primary requirement matrix, $\mathbf{R}$, is generated randomly for our simulations as follows:

$$
\mathbf{R}=\left(\begin{array}{llllllll}
2 & 3 & 1 & 2 & 2 & 4 & 3 & 4 \\
1 & 3 & 1 & 2 & 4 & 2 & 3 & 3
\end{array}\right) .
$$

The development cost of an entire end-product is about $\$ 288,000$ and the development cost of each variant module is proportionately determined according to its relative value. Further, it is reasonable that developing a higher-end module option often costs more than developing a lower-end module option. Therefore, we increase development cost for each module option by $5 \%$ for one performance level higher.

The cost of good sold (COGS) of a finished product is estimated at about $70 \%$ of its retail price, while about $70 \%-75 \%$ 


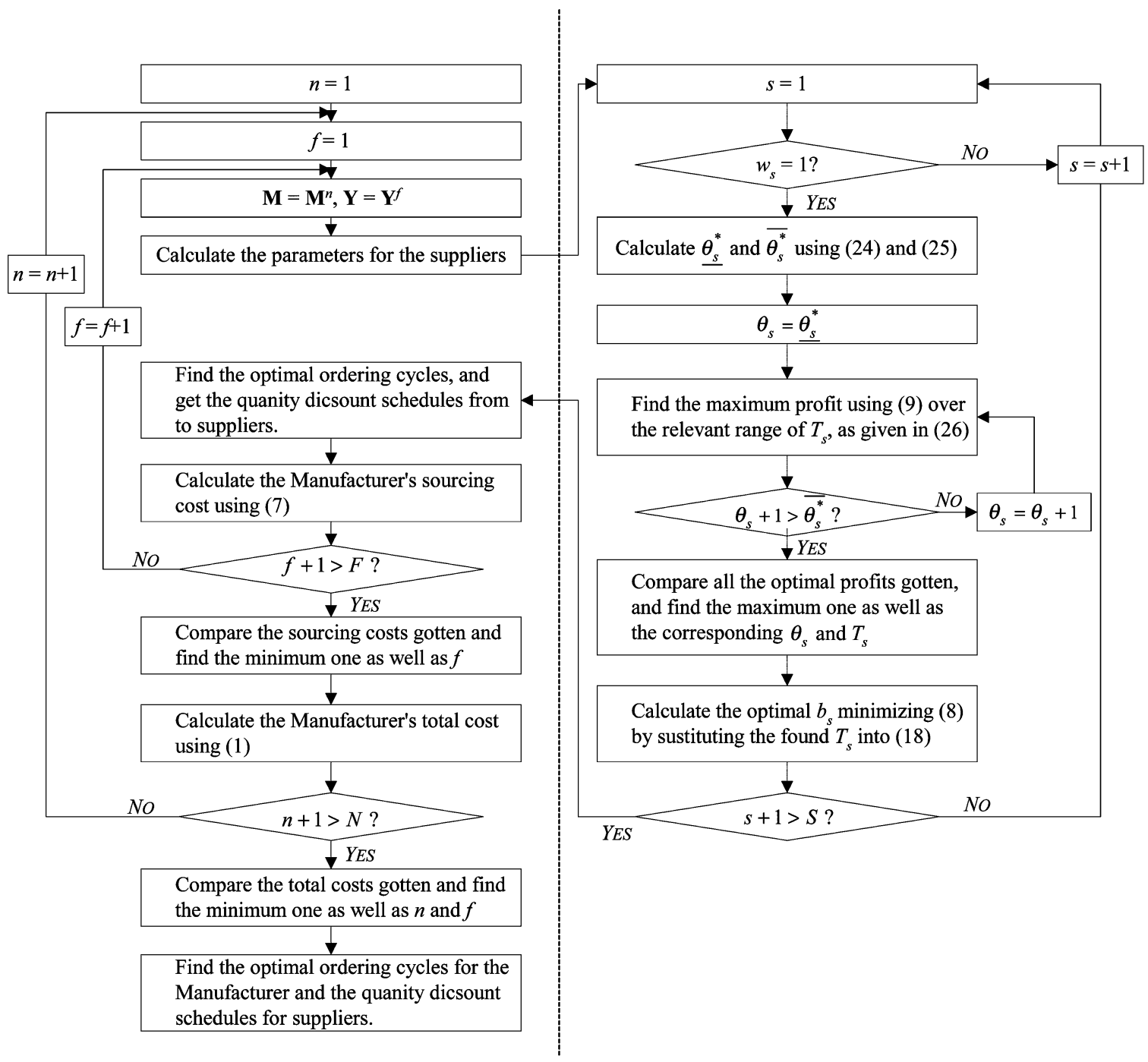

Fig. 4. Solution procedure.

of the COGS is budgeted for raw material cost by the Manufacturer. With the retail price of has been set at $\$ 1,500$ as above, the total raw material cost of a finished product is about $\$ 735$. Again, the material cost of each variant module is proportionately determined according to its relative value, and increases by $5 \%$ for one performance level higher.

From the perspective of the suppliers, as we have stated in Section III, there are two kinds of suppliers for each variant module, i.e., the supplier with high flexibility and with low flexibility. The former one can produce all the module options of the variant module; the latter one can only produce either the lower or the higher half module options of the variant module. Therefore, we assign three suppliers to each variant module, of which two are with low flexibility and one is with high capability. It is reasonable to assume that the prices of the module options from the low-flexibility suppliers are lower than those from the high-flexibility suppliers, as well as the manufacturing costs and setup costs occur at the corresponding suppliers. Thus, we set the price of the same module option charged by the low-flexibility suppliers $0.06 \%$ lower than the price charged by the high-flexibility suppliers. We also set the manufacturing cost and setup cost of the same module
TABLE III

VALUES OF VARIOUS PARAMETERS OF THE MODEL

\begin{tabular}{ccccccc}
\hline Model parameters: & $A$ & $h$ & $A_{s}$ & $V_{s}$ & $h_{s}$ & $\varepsilon_{j k s}$ \\
\hline Values: & 300 & 4 & 100 & 300 & 1 & $0.05 p_{j k s}^{0}$ \\
\hline
\end{tabular}

option occurring at the low-flexibility suppliers $20 \%$ lower than those occurring at the high-flexibility suppliers. Again, the COGS of a module option at the suppliers is about $70 \%$ of its original price. Finally, the average fixed setup costs for module options in $m_{1}$ and $m_{2}$ are estimated at about $\$ 400$ and $\$ 200$, respectively.

The values used for other model parameters in our simulations are given in Table III.

Among the various game model parameters, lifetime demand volume of the platform products, $D$, is the only important one which concerns all the players greatly. At the age of mass customization, there is a trend toward a high level of product variety and short product life cycles which leads to a lower lifetime worldwide demand than that in a mass production system. However, what is the relationship between the level of product variety as well as other strategic decisions of all the players and 


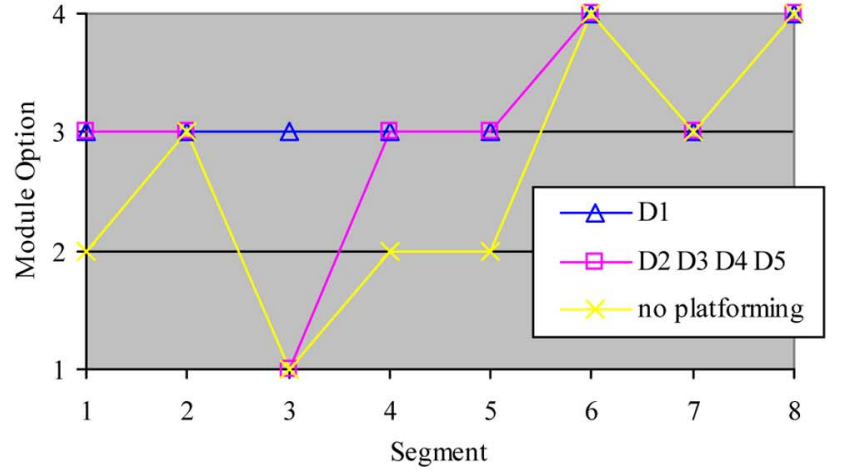

(a)

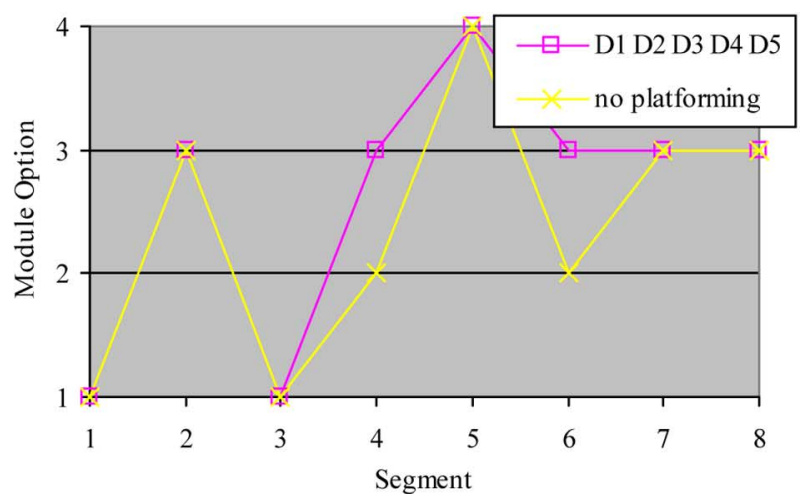

(b)

Fig. 5. Platform products configuration results under each level of $D$. (a) $m_{1}$ and (b) $m_{2}$.

the lifetime demand volume? In this paper, we are especially interested in this problem in our simulations. We select five levels of $D$ in our simulations which include 0.06 million units (denoted by $D_{1}$ ), 0.25 million units (denoted by $D_{2}$ ), 0.5 million units (denoted by $D_{3}$ ), 1 million units (denoted by $D_{4}$ ), and 2 million units (denoted by $D_{5}$ ).

For each level of $D$, the decisions of each player in the case where the primary requirement of market segments have been taken for the Manufacturer's platform products configuration decision would be determined first. In other words, platforming is not allowed in this case. We call it "no platforming" or NP case. Then, the decisions of each player in the case where the platform products configuration has not been decided yet would be determined. In other words, platforming is allowed in this case, and we call it "with platforming" or WP case. The results of both cases would be compared to find out how platforming strategy impacts the behaviors of all the players.

In order to interpret the PPD decisions of the Manufacturer, we use the term "the level of customization" to indicate the optimal number of product variants included in the end product family. That is, this level measures the degree of product variety of the product family. For the sourcing decisions of each variant module made by the Manufacturer, we use the term "high sourcing" to indicate that all the module options are purchased from suppliers with high flexibility and the term "low sourcing" to indicate that the module options are purchased from suppliers with low flexibility.

\section{B. Simulation Results}

After the lifetime of the studied platform products described above is assumed as two years, the optimal solutions of the ICPPSC game are searched through the proposed solution procedure. We present the simulation results in the following.

First, we give the results of PPD decisions of the Manufacturer in Fig. 5 which shows the comparison between the $\mathbf{R}$ of NP case and the optimal $\mathbf{M}$ of WP case under each level of $D$ for $m_{1}$ and $m_{2}$, respectively. As we can see from Fig. 5, products in WP case are different from those in NP case, which results in the decreases of the number of module options used for $m_{1}$ and $m_{2}$, respectively, in the WP case. Specifically, in WP case, only 2 module options are used for $m_{1}$ under $D_{1}$, and 3 module options are used for $m_{1}$ under $D_{2}-D_{5}$, while 3 module options are used for $m_{2}$ under each level of $D$. However, all the 4 module options are used for $m_{1}$ and $m_{2}$, respectively, in NP case. The decreases in the numbers of module options used lead to a decrease of the level of customization of the platform products, as well as the reductions of development cost from NP case to WP case. In addition, the level of customization in the WP case increases as $D$ increases. This implies that the pressure of mass customization of the Manufacturer is high when $D$ is low. In other words, the Manufacturer will have more inclination to offer highly mass customized products when lifetime demand volume is high.

Next, we present the changes of the values of the Manufacturer's objective and its elementary parts between the NP and WP cases under each level of $D$ in Fig. 6. Fig. 6(a) shows the decreases of total costs and the $D C$ s while Fig. 6(b) presents the changes of the elementary costs in $S C$.

We can see from Fig. 6(a) that the total cost and $D C$ are always lower in WP case. Moreover, the reduction in the $D C$ decreases as $D$ increases because the level of customization increases. On the other hand, through the Manufacturer's objective function presented in Section IV, we can see that the discrepancy between the decreases of the total cost and the $D C$ is the change of the $S C$. Then we can figure out from Fig. 6(a) that Manufacturer's $S C$ is higher in WP case under demand levels $D_{1}-D_{4}$, and is lower in WP case under demand level $D_{5}$. This can be explained as follows. When $D$ is low, the level of customization is low and the module options used have higher performance levels as well as prices in WP case because of our option replacement assumption. Therefore, the $S C$ is higher in WP case when $D$ is low. However, the total cost still decreases in WP case because of the reduction of $D C$. As $D$ increases, the level of customization increases and more low-end module options with lower prices are used. Thus, the increase of the $S C$ in WP case decreases even becomes negative. That is, the $S C$ is lower in the WP case.

Fig. 6(b) presents the changes of the elementary costs in $S C$, i.e., the increases of $P u r C$ and $\operatorname{OrdC}$, and the decrease of $\operatorname{InvC}$, from the NP case to the WP case under each level of $D$. Again, we can see from the downward trend of the PurC's increase in this figure that the Manufacturer's sourcing pressure is comparatively high when $D$ is low and this pressure decreases as $D$ increases, which is coincident with what we have discussed above. 


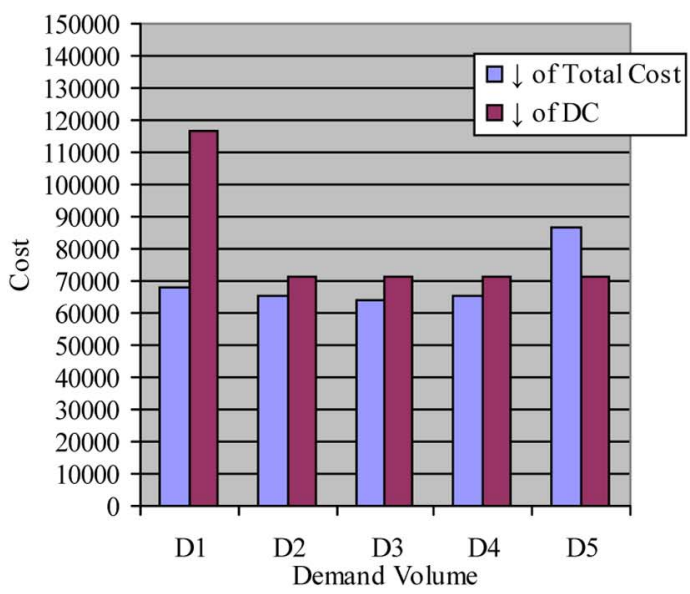

(a)

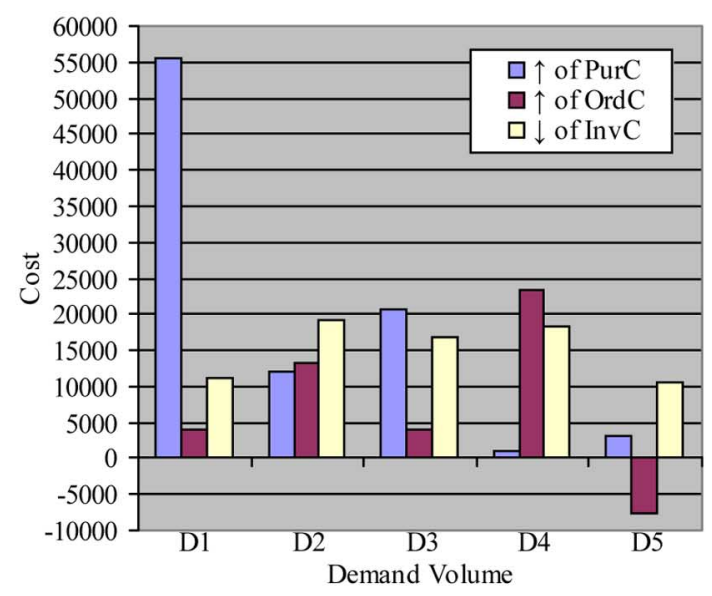

(b)

Fig. 6. Various costs of the Manufacturer under various levels of $D$. (a) Total cost and $D C$ (b) Elementary costs of $S C$.

In addition, we can see that under the impact of platforming, the $\operatorname{Inv} C$ of the Manufacturer decreases to some extent under each level of $D$.

Now we display the simulation results of the suppliers' objectives under each level of $D$ in Fig. 7. Just as in Fig. 1, $S_{1}$, $S_{2}$ and $S_{4}, S_{5}$ are suppliers with low flexibility while $S_{3}$ and $S_{6}$ are suppliers with high flexibility for $m_{1}$ and $m_{2}$, respectively. As only selected suppliers would have profits, the results in Fig. 7 can also reflect the supplier selection decisions of the Manufacturer.

We consider the supplier selection decisions of the Manufacturer first. We can see that the Manufacturer chooses low sourcing strategy in the WP case in stead of high sourcing strategy in the NP case. On the other hand, when $D$ increases, there is a trend of using the low sourcing strategy in both cases for the Manufacturer. Then, from the perspective of the suppliers, we can see from Fig. 7 that for the suppliers of each variant module, the profit of a single supplier (when the Manufacturer uses high sourcing in both cases) or the sum of the profits of the suppliers as a group (otherwise) increases in the WP case. This implies that the platforming strategy is of benefit to the suppliers either. However, such benefit mostly goes to the suppliers who can produce the high-end module options (i.e., $S_{2}$ and $S_{5}$ ).

In the above, we have discussed the results about the impacts of platforming strategy on the objectives of the Manufacturer and the suppliers, and the PPD and supplier selection decisions of the Manufacturer at the first move of the dynamic configuration game. Now, let us look at the results about the optimal decisions of the suppliers and the Manufacturer at the second and the third move of the game. Such decisions include the price discount rate, $b_{s}$, and ordering frequency, $\theta_{s}$, decisions of each selected supplier (at the second move) and the Manufacturer's ordering cycle to each selected supplier, $T_{s}$ (at the third move). The simulation results of these decision variables in both the NP and WP cases under each level of $D$ are shown in Table IV.

We can see from Table IV that, the ordering cycles of the suppliers who can only produce the low-end module options (i.e., $S_{1}$ and $S_{4}$ ) decrease in the WP case, while the ordering cycles of the other suppliers (i.e., those who can produce the high-end module options) increase in the WP case. On the other hand, we can see from Table IV that the discount rates offered by the suppliers decrease in the WP case. This can imply that the Manufacturer tends to accept higher prices from suppliers, or the suppliers can make higher sale prices under the impact of platforming.

About the decisions at the final move of the Manufacturer, we can see that when $D$ is low, the Manufacturer orders more times in the WP case. As $D$ increases, the Manufacturer's ordering frequency decreases in the WP case. Moreover, most of his orders go to the suppliers who can produce the high-end module options.

Finally, we present the results about how the platforming strategy of the Manufacturer is affected by the suppliers' flexibilities. In order to achieve this, we design some experiments in which the sourcing strategy of the Manufacturer are restricted to only the high sourcing or only the low sourcing. The results of the Manufacturer's PPD decisions in these experiments are shown in Fig. 8. In this figure, "high" or "low" means the Manufacturer's sourcing strategy is restricted to high or low sourcing. We can see from this figure that the flexibilities of the suppliers do affect the Manufacturer's PPD decisions, and high flexibility of the suppliers' capability leads to a high level of customization.

\section{Managerial Implications}

Based on the results obtained from the simulation analyses presented above, we can draw a general conclusion that there do exist mutual impacts between the PPD and SCC decisions among the players in our configuration game of the ICPPSC problem. In this section, we will wrap up our findings and some main implications regarding the impacts of platforming strategy on the benefits and decisions of all the players, and the impacts of supply chain decisions and parameters on the platforming strategy.

First, the total cost of the Manufacturer decreases while for the suppliers of each variant module, the profit of a single supplier (when the Manufacturer uses high sourcing in both cases) or the sum of the profits of the suppliers as a group (otherwise) increases in the WP case. This implies 


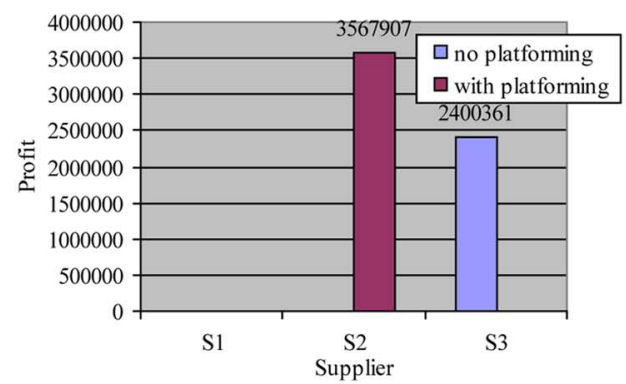

(a)

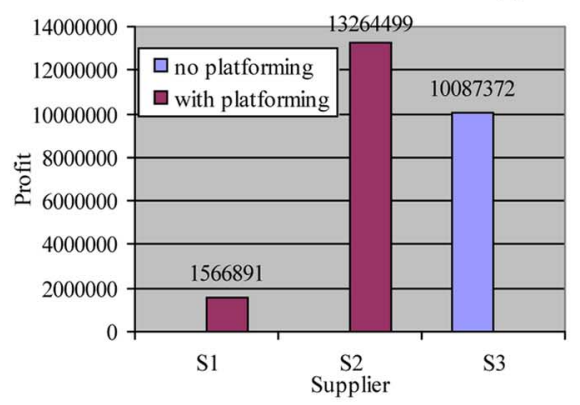

(b)

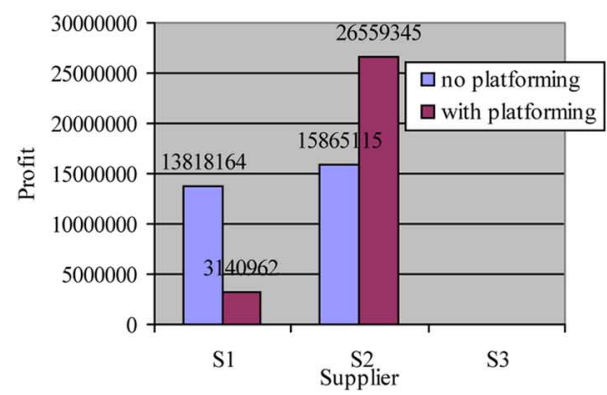

(c)

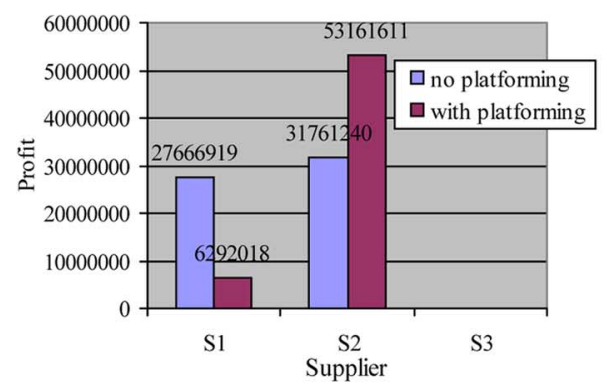

(d)

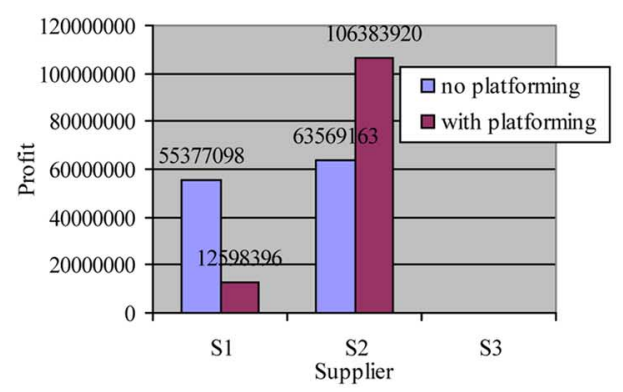

(e)

Fig. 7. PPD decisions under different suppliers' flexibilities and level of $D$.

that the platforming strategy is of benefit to both the Manufacturer and the suppliers. Specifically, such benefit for the suppliers of each variant module mostly goes to those who
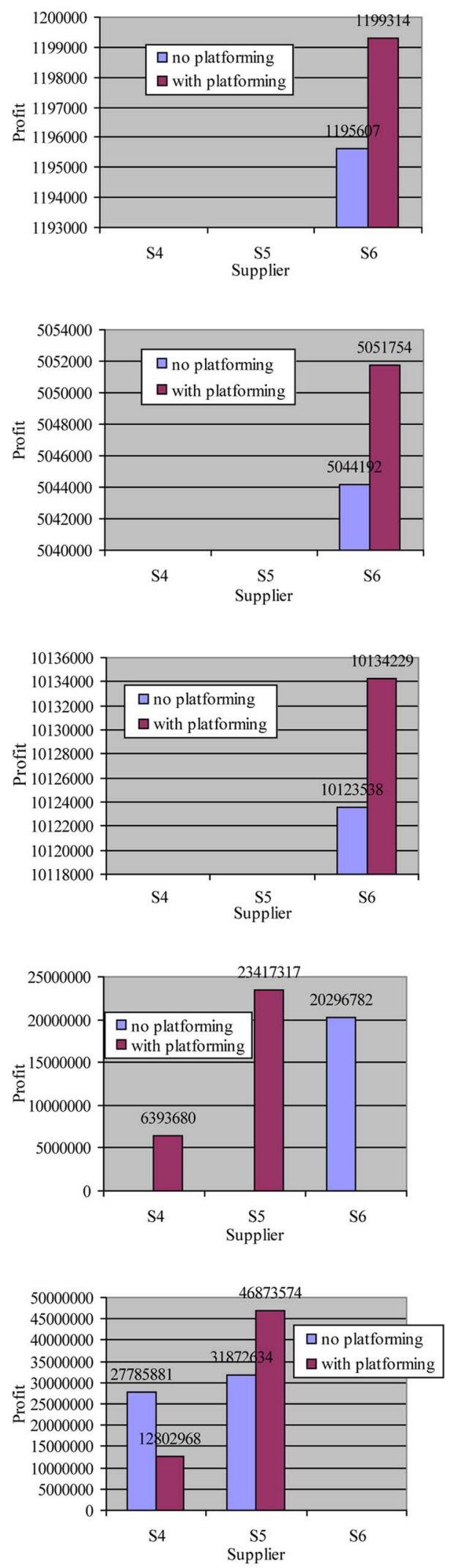

can produce the high-end module options at the cost of the profits of the suppliers who produce only the low-end module options. 
TABLE IV

Decisions of SuPPliers AND the Manufacturer Under Each LeVel of $D$.

\begin{tabular}{|c|c|c|c|c|c|c|c|c|c|c|c|c|c|}
\hline & & \multicolumn{2}{|c|}{$\mathbf{S}_{1}$} & \multicolumn{2}{|c|}{$\mathbf{S}_{\mathbf{2}}$} & \multicolumn{2}{|c|}{$\mathbf{S}_{\mathbf{3}}$} & \multicolumn{2}{|c|}{$\mathbf{S}_{4}$} & \multicolumn{2}{|c|}{$\mathbf{S}_{5}$} & \multicolumn{2}{|c|}{$S_{6}$} \\
\hline & & NP & WP & $\mathrm{NP}$ & WP & $\mathrm{NP}$ & WP & NP & WP & NP & WP & NP & $\overline{\mathrm{WP}}$ \\
\hline \multirow{3}{*}{$D_{1}$} & $b_{s}\left(\times 10^{-5}\right)$ & & & & 4.0 & 5.5 & & & & & & 4.5 & 2.3 \\
\hline & $\theta_{s}$ & & & & 1 & 1 & & & & & & 1 & 2 \\
\hline & $T_{s}$ & & & & 18 & 12 & & & & & & 16 & 23 \\
\hline \multirow{3}{*}{$D_{2}$} & $b_{s}\left(\times 10^{-5}\right)$ & & 0.5 & & 1.1 & 1.3 & & & & & & 1.1 & 0.5 \\
\hline & $\theta_{s}$ & & 2 & & 1 & 1 & & & & & & 1 & 2 \\
\hline & $T_{s}$ & & 19 & & 34 & 24 & & & & & & 33 & 48 \\
\hline \multirow{3}{*}{$D$} & $b_{s}\left(\times 10^{-5}\right)$ & 0.6 & 0.2 & 0.9 & 0.6 & & & & & & & 0.5 & 0.3 \\
\hline & $\theta_{s}$ & 2 & 2 & 1 & 1 & & & & & & & 1 & 2 \\
\hline & $T_{s}$ & 45 & 27 & 37 & 48 & & & & & & & 47 & 67 \\
\hline \multirow{3}{*}{$D_{4}$} & $b_{s}\left(\times 10^{-5}\right)$ & 0.3 & 0.1 & 0.5 & 0.3 & & & & 0 & & 0 & 0.3 & \\
\hline & $\theta_{s}$ & 2 & 2 & 1 & 1 & & & & 2 & & 2 & 1 & \\
\hline & $T_{s}$ & 64 & 38 & 53 & 69 & & & & 54 & & 101 & 67 & \\
\hline \multirow{3}{*}{$D_{5}$} & $b_{s}\left(\times 10^{-5}\right)$ & 0.1 & 0 & 0.2 & 0.1 & & & 0 & 0 & 0 & 0 & & \\
\hline & $\theta_{s}$ & 2 & 2 & 1 & 1 & & & 2 & 2 & 2 & 2 & & \\
\hline & $T_{s}$ & 91 & 54 & 75 & 97 & & & 112 & 77 & 118 & 143 & & \\
\hline
\end{tabular}

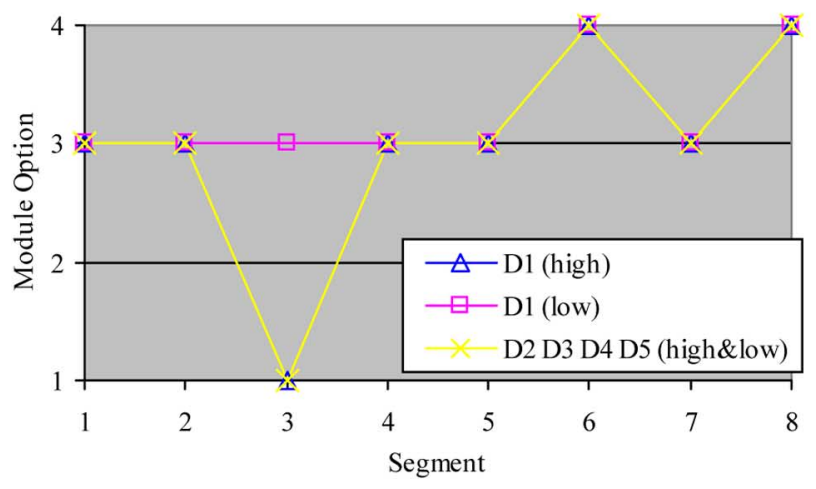

(a)

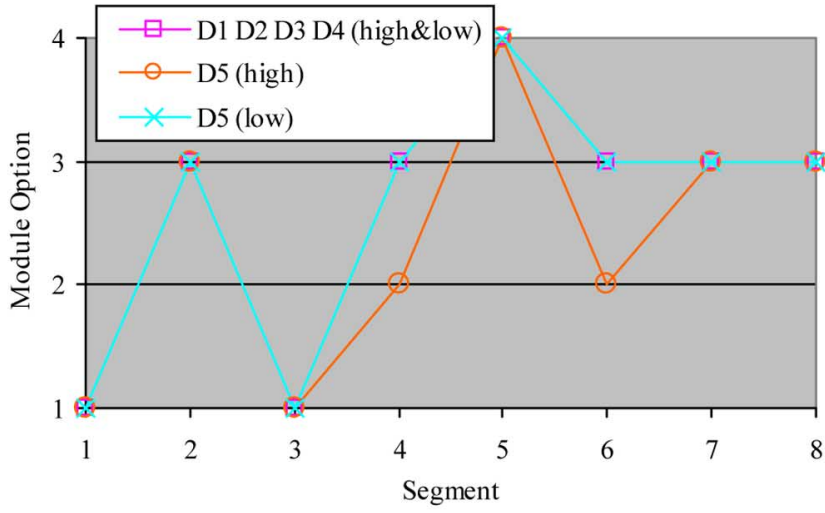

(b)

Fig. 8. PPD decisions under different suppliers' flexibilities and level of $D$. (a) $m_{1}$ and (b) $m_{2}$.

Second, under the impact of platforming, the Manufacturer's inventory cost enjoys a generally decreasing trend. In addition, the platforming strategy increases the Manufacturer's purchasing costs especially when $D$ is low. This is because when $D$ is low, the level of customization is low and the high-end module options are ordered to replace the low-end ones. However, this still results in overall benefits for the Manufacturer due to savings in other areas.

Third, the platforming strategy leads the Manufacturer to use the low sourcing strategy or the suppliers with low flexibility in stead of high sourcing strategy when $D$ is low. This implies that when $D$ is low and the Manufacturer decides to provide the customers with the products exactly the same as they require, the suppliers would tend to build up a higher flexibility. Otherwise, the suppliers would like to build up a lower flexibility especially for producing high-end module options.

Fourth, the Manufacturer enjoys better benefits by producing platform products with lower level of customization when $D$ is low. As $D$ increases, the Manufacturer's desire to offer highly customized products becomes stronger.

Fifth, the Manufacturer tends to accept higher prices from the suppliers under the impact of platforming so that the suppliers share the benefits of platforming. In addition, under the impact of platforming, the suppliers who can produce the high-end module options order more frequently, and the Manufacturer's total ordering frequency increases when $D$ is low and decreases when $D$ is high while most of his orders go to the suppliers who can produce the high-end module options.

Finally, the flexibility of the suppliers' capability can affect the Manufacturer's PPD decisions. When the flexibility is high, the level of customization of the end-products decided by the Manufacturer becomes higher.

\section{Further Remarks on the Game Model}

The game model used in this paper is sequential with the Manufacturer taking a leading/dominating role by moving first 
to determine a few decision variables. In this setting, once the manufacturer makes the supplier selection decision, the chosen suppliers get more power in the channel. In this sense, the manufacturer apparently looses the opportunity to benefit from the price competition among all the alternative suppliers. This implies that the suppliers make pricing decisions first before the manufacturer makes the supplier selection decision. A game model with suppliers as leaders is very complicated because of multiplicity of suppliers and complexity of configuration and supplier selection decisions. There are several good reasons for us to consider the manufacturer-led game in this research. First, in our research problem, there is no information exchanging nor competitive relationship between suppliers. Therefore, there is no wider pool as suppliers make their pricing decisions independent of each other. We can formulate a Nash subgame for suppliers to consider their competitive relationships, and then incorporate all the subgames in the overall game. Experience shows that the resulting game is extremely complicated and the efficiency of the computational solution is of major concern [46]. Moreover, in our research problem, the flexibility or capability of each supplier is different. Some suppliers can only produce the higher or lower end of the module options while other suppliers can produce all the module options. Therefore, it is not practical for them to compete. For example, the supplier who can only produce the lower end module options cannot compete with the supplier who can only produce the higher end module options.

Second, the supplier selection decision of the Manufacturer is required when we optimize the suppliers' model. As we have assumed that single sourcing policy is optimal for the Manufacturer (see Assumption 4), once supplier selection decision of the Manufacturer is given, the total demand volume of module options to each supplier can be gotten. The total demand volume of each supplier is an input parameter of the supplier's model in this paper, just like many other quantity discount models [38], [39], [40]. In other words, a supplier's pricing decision is affected by its total demand volume, and it is difficult for this supplier to make pricing decision if the demand volume is unknown. This is true in practice. In addition, further research is needed if the single sourcing assumption is replaced by allowing multiple sourcing.

Finally, our solution approach proposed in this paper is an enumerative method. The Manufacturer evaluates every possible supplier selection decision based on suppliers' rational reactions and then selects an optimal one. Therefore, once the manufacturer makes his supplier selection decision, the chosen suppliers do not necessarily get more power in the channel. Instead, the only player with more power is still the Manufacturer in our game. As our solution procedure is global and enumerative, the solution gotten in this paper should be optimal.

\section{CONCLUSION AND FUTURE WORK}

The work presented in this paper makes several contributions. First, this research has examined the integrated configuration of platform products and supply chains, and more importantly GT has been used to formulate and solve this emerging and complex problem. This is an early but important addition to the literature where virtually little work has been done using the game to reflect the supply chain environment. The game model allows us to mimic the cooperation and competition situation between enterprises in the supply chain when they make design decisions for the products, processes and supply sources. This paper forms a foundation for further systematic and comprehensive studies on different supply chain coordination/competition environments.

The formulation and solution of the supply chain configuration game is another important contribution of this paper. The configuration game is complicated by the fact that supplier selection itself is a decision variable. This is very different from other types of supply chain games where the suppliers are normally selected already and, therefore, they are game players. In the configuration problem, suppliers may not yet been selected and it becomes an issue if they should participate in the game as players. We deal with this problem using a three-move dynamic game. Supplier selection is accomplished in the first move by the manufacturer. We have also used both analytical and computational methods for the derivation of the optimal ranges of players' rational reactions, and the development of the solution procedure.

This paper has also contributed to the understanding and knowledge about the mutual impacts of the configuration decisions through a series of simulations using the proposed game model and solution procedure. We have derived some interesting general observations and managerial implications from the specific case application and simulations.

An immediate extension of this paper is to conduct more analyses using more decision parameters and variables to obtain more implications from our configuration game of ICPPSC problem. In this case, the problem complexity is increased. The current solution procedure proposed in this paper is enumerative and, therefore, has a comparatively low computational efficiency. A more sophisticated solution algorithm is required to solve the complex model for better efficiency and effectiveness. We plan to develop a parallel hybrid coevolutionary algorithm for solving the game models.

In this paper, the suppliers' decisions are comparatively simple and they only offer quantity discounts in this game. The suppliers may also offer volume discounts in addition to quantity discounts and have more decision variables. As for the Manufacturer's objective function, it may be extended to a profit model which takes the Manufacturer's pricing policy as a new decision variable. Finally, we did not consider the locations of the players as well as the transportation lead-time between each player in this paper. Our extended model may take these into consideration.

Configuration games need further investigations. It is important to use different types of game models to simulate various coordination strategies in SCM, from fully integrated, cooperative to fully competitive, and from simultaneous to sequential. First, the game model used in this paper is sequential. The Manufacturer takes a leading/dominating role by moving first to determine a few decision variables. In this setting, once the manufacturer makes the supplier selection decision, the chosen 
suppliers get more power in the channel. In this sense, the manufacturer would loose the opportunity to benefit from the price competition among all the alternative suppliers. This raises an issue who moves first. It would be interesting to see the outcome of the game where the manufacturer makes suppliers move first to commit to their prices prior to supplier selection decision. Alternatively, these two decisions are made simultaneously in a simultaneous game. In both cases, the resulting game models are completely different and much more complicated to solve. This is an area for further investigation. Second, the game model used in this paper is noncooperative. It would be interesting to investigate other game models with closer cooperation between the Manufacturer and suppliers (e.g., fully integrated supply chain and cooperative coalitional games). In a coalitional cooperative game, individual suppliers cooperate to meet customer demand which cannot be met individually. Third, the competitive relationship between suppliers in the game also deserves further study. Through competition, the Manufacturer may get lower prices from suppliers and, therefore, get a higher payoff. This can be done using a competitive simultaneous game or subgame. Fourth, an assumption was made in this research upon single sourcing. If multisourcing is allowed, how the game model should be revised and the solution technique be extended requires further study. Finally, it would be interesting to compare the results obtained in the game model used in this paper with those using the game models mentioned above. Such comparative analyses will provide significant insights for integrated configuration of platform products and supply chains under different coordination schemes.

Finally, while the game model presented in the paper was for a two-echelon supply chain: the Manufacturer and its suppliers. It is desirable to include other echelons such as retailers and distributors. The game-theoretic approach presented in this paper can be extended to solve such complex chain. For a three-echelon supply chain (supplier-manufacturer-retailer), for example, it can be explored by applying the game-theoretic approach proposed in this paper on both ends of the chain. However, it is worth pointing out that it is not easy to consider multitier supply chains in a game model although several such models exist in the literature. Most of such game models are associated with some special assumptions. It is our ultimate intention to extend our work in this paper for multitier supply chain games. Our planned approach is to formulate a game for the pair-wise twotier supply chains and then propagate the solution into the next tier in a similar way. We have conducted some investigations into the two-tier supply chains 1) retailers versus manufacturer reported separately in another paper [46] and 2) manufacturer versus suppliers (as in this paper) in two separate researches. This combination of retailers-manufacturer game and manufacturer-suppliers game into one game is itself novel, deserving substantial further research efforts.

\section{ACKNOWLEDGMENT}

Authors would also like to thanks the referees for their very insightful and constructive comments and suggestions.

\section{REFERENCES}

[1] B. J. Pine, II, Mass Customization: The New Frontier in Business Competition. Boston, MA: Harvard Bus. Sch. Press, 1993.

[2] K. T. Ulrich and S. D. Eppinger, Product Design and Development. New York: McGraw-Hill, 1995.

[3] A. K. Chakravarty and N. Balakrishnan, "Achieving product variety through optimal choice of module variations," IIE Trans., vol. 33, pp. 587-598, 2001.

[4] S. Gupta and V. Krishnan, "Integrated component and supplier selection for a product family," Production Operations Manage., vol. 8, no. 2, pp. 163-182, 1999.

[5] V. Krishnan and S. Gupta, "Appropriateness and impact of platformbased product development," Manage. Sci., vol. 47, no. 1, pp. 52-68, 2001.

[6] B. J. Park, "A framework for integrating product platform development with global supply chain configuration," Ph.D. dissertation, Georgia Inst. Technol., Atlanta, GA, 2001.

[7] A. Meca, J. Timmer, I. Garcia-Jurado, and P. Borm, "Inventory games," Eur. J. Operational Res., vol. 156, pp. 127-139, 2004.

[8] A. Meca, I. García-Jurado, and P. Borm, "Cooperation and competition in inventory games," Math. Meth. Operations Res., vol. 57, pp. 481-493, 2003.

[9] H. Hamers, F. Klijn, and J. Suijs, "On the balancedness of multiple machine sequencing games," Eur. J. Operational Res., vol. 119, pp. 678-691, 1999.

[10] E. Altman and G. Koole, "Stochastic scheduling games with markov decision arrival processes," Comput. Math. Appl., vol. 26, no. 6, pp. 141-148, 1993.

[11] C. Forza and M. J. Rungtusanatham, "Coordinating product design, process design, and supply chain design decisions," J. Operations Manage., vol. 23, no. 3-4, pp. 257-418, 2005.

[12] C. Yano and G. Dobson, "Profit-optimizing product line design, selection and pricing with manufacturing cost consideration," in Product Variety Management: Research Advances, E. b. T. H. Ho and C. S. Tang, Eds. Norwell, MA: Kluwer Academic, 1998.

[13] U. W. Thonemann and J. R. Bradley, "The effect of product variety on supply-chain performance," Eur. J. Operational Res., vol. 143, pp. 548-556, 2002.

[14] R. Kohli and R. Sukumar, "Heuristics for product-line design using conjoint analysis," Manage. Sci., vol. 36, no. 12, pp. 1464-1478, 1990.

[15] L. O. Morgan, R. L. Daniels, and P. Kouvelis, "Marketing/manufacturing trade-offs in product line management," IIE Trans., vol. 33, pp. 949-962, 2001.

[16] N. Raman and D. Chhajed, "Simultaneous determination of product attributes and prices, and production processes in product-line design," J. Operations Manage., vol. 12, pp. 187-204, 1995.

[17] M. H. Meyer and A. P. Lehnerd, The Power of Product Platforms: Building Values and Cost Leadership. New York: The Free Press, 1997.

[18] D. Robertson and K. Ulrich, "Planning for product platforms," MIT Sloan Manage. Rev., vol. 39, no. 4, pp. 19-31, 1998.

[19] D. P. Rutenberg, "Design commonality to reduce multi-item inventory: optimal depth of a product line," Operations Res., vol. 19, no. 2, pp. 491-509, 1969.

[20] D. A. Collier, "The measurement and operating benefits of component part commonality," Decision Sci., vol. 12, no. 1, pp. 85-96, 1981.

[21] — "Aggregate safety stock levels and component part commonality," Manage. Sci., vol. 28, no. 11, pp. 1296-1303, 1982.

[22] W. L. Berry, W. J. Tallon, and W. J. Boe, "Product structure analysis for the master scheduling of assemble-to-order products," Int. J. Operations Production Manage., vol. 12, no. 11, pp. 24-41, 1992.

[23] K. R. Baker, "Safety stocks and commonality," J. Operations Manage., vol. 6, no. 1, pp. 13-22, 1985.

[24] A. Dogramaci, "Design of common components considering implications of inventory costs and forecasting," AIIE Trans., vol. 11, no. 2, pp. 129-135, 1979.

[25] W. C. Benton and L. J. Krajewski, "Vendor performance and alternative manufacturing environments," Decision Sci., vol. 21, no. 2, pp. 403-415, 1990.

[26] Y. Gerchak and M. Henig, "Component commonality in assemble-toorder systems: models and properties," Naval Res. Logistics, vol. 36, pp. 61-68, 1989.

[27] Y. Gerchak, M. J. Magazine, and A. B. Gamble, "Component commonality with service level requirements," Manage. Sci., vol. 34, no. 6, pp. 753-760, 1988. 
[28] K. Ramdas and M. S. Sawhney, "A cross-functional approach to evaluating multiple line extensions for assembled products," Manage. Sci., vol. 47 , no. 1 , pp. 22-36, 2001.

[29] B. Kim, J. M. Y. Leung, K. T. Park, G. Zhang, and S. Lee, "Configuring a manufacturing firm's supply network with multiple suppliers," IIE Trans., vol. 34, pp. 663-677, 2002.

[30] F. Salvador, C. Forza, and M. Rungtusanatham, "Modularity, product variety, production volume, and component sourcing: theorizing beyond generic prescriptions," J. Operations Manage., vol. 20, pp. 549-575, 2002.

[31] G. Cachon and S. Netessine, "Game theory in supply chain analysis," in Supply Chain Analysis in the E-Business Era, E. b. D. Simchi-Levi, S. D. Wu, and M. Shen, Eds. Norwell, MA: Kluwer Academic, 2004, ch. 2 .

[32] M. Slikker, J. Fransoo, and M. Wouters, "Cooperation between multiple news-vendors with transshipments," Eur. J. Operational Res., vol. 167, no. 2, pp. 370-380, 2005.

[33] M. A. Lariviere and E. L. Porteus, "Selling to the newsvendor: an analysis of price-only contracts," Manuf. Service Operations Manage., vol. 3, pp. 293-305, 2001.

[34] J. Y. Bakos and E. Brynjolfsson, "Information technology, incentives, and the optimal number of suppliers," J. Manage. Inf. Syst., vol. 10, no. 2, pp. 37-54, 1993.

[35] H. Rhim, T. H. Ho, and U. S. Karmarkar, "Competitive location, production, and market selection," Eur. J. Operational Res., vol. 149, pp. 211-228, 2003

[36] S. Talluri and R. C. Baker, "A multi-phase mathematical programming approach for effective supply chain design," Eur. J. Operational Res., vol. 141 , pp. 544-558, 2002.

[37] T. Moyaux, B. Chaib-draa, and S. D'Amours, "The impact of information sharing on the efficiency of an ordering approach in reducing the bullwhip effect," IEEE Trans. Syst., Man, Cybern., 2004, submitted for publication.

[38] R. Lal and R. Staelin, "An approach for developing an optimal discount pricing policy," Manage. Sci., vol. 30, pp. 1524-1539, 1984.

[39] M. Parlar and Q. Wang, "An approach for developing an optimal discount pricing policy," Manage. Sci., vol. 17, no. 2, pp. 34-41, 1994.

[40] M. J. Rosenblatt and H. L. Lee, "Discounting decisions in a supplierbuyer relationship with a linear buyer's demand," IIE Trans., vol. 26, pp. 388-395, 1985.

[41] Q. Wang, "Determination of suppliers' optimal quantity discount schedules with heterogeneous buyers," Naval Res. Logistics, vol. 49, pp. 46-59, 2002.

[42] S. Viswanathan and Q. Wang, "Discount pricing decisions in distribution channels with price-sensitive demand," Eur. J. Operational Res., vol. 149, pp. 571-587, 2003.

[43] A. V. Smirnov, L. Sheremetov, N. Chilov, and J. C. R. Cortés, "Softcomputing technologies for configuration of cooperative supply chain," Appl. Soft Computing, vol. 4, no. 1, pp. 87-107, 2004.

[44] D. Zhang, J. Dong, and A. Nagurney, "A supply chain network economy: Modeling and qualitative analysis," in Innovations Financial and Economic Networks. Northampton, MA: Edward Elgar, 2003.

[45] H. L. Lee and M. J. Rosenblatt, "A generalized quantity discount pricing model to increase supplier's profits," Manage. Sci., vol. 32, pp. 1177-1185, 1986.

[46] Y. G. Yu, G. Q. Huang, and L. Liang, "Stackelberg game theory model for optimizing advertising, pricing, and inventory policies in vendor managed inventory (VMI) supply chains," IEEE Trans. Autom. Sci. Eng., submitted for publication.

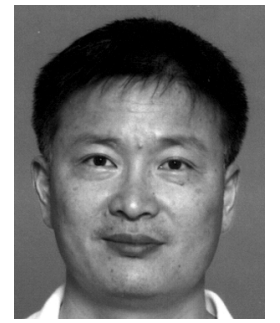

George Q. Huang received the B.Eng. degree in mechanical engineering from Southeast University, Nanjing, China, and the Ph.D. degree in mechanical engineering from Cardiff University, Cardiff, U.K., in 1983 and 1991, respectively.

He is currently an Associate Professor at The University of Hong Kong. His main research interests include platform products for mass customization, supply chain configuration, grid design and manufacturing, and computational game theory. He has published extensively in these topics, including over 70 journal papers, two monographs: Cooperating Expert Systems in Mechanical Design and Internet Applications in Product Design and Manufacturing, respectively, and an edited reference book: Design for X: Concurrent Engineering Imperatives.

Dr. Huang is a Chartered Engineer, and a member of Institution of Electrical Engineers (U.K.), HKIE, IIE, and ASME.

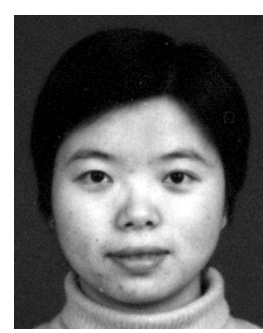

Xin Yan Zhang received the B.E. and M.S. degrees in mechanical engineering from Huazhong University of Science and Technology, Wuhan, China, in 1999 and 2002, respectively. She is currently working towards the Ph.D. degree in the Department of Industrial and Manufacturing Systems Engineering, the University of Hong Kong, Hong Kong.

Her research interests include platform products for mass customization, supply chain configuration, computational game theory, computer-aided process planning, and product data management.

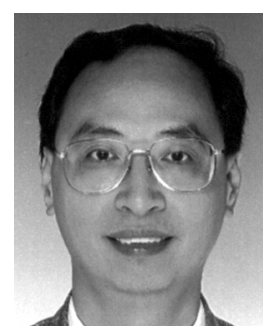

Victor H. Y. Lo received the B.S. degree in production engineering, the M.Sc. degree in industrial engineering, and the Ph.D. degree in engineering management.

$\mathrm{He}$ has authored/edited of three books. At the University of Hong Kong, Hong Kong, his teaching and research activities are related to various aspects of quality engineering and engineering management. He maintains very close contacts with industries in Hong Kong and mainland China. He has served the society in various capacities such as Council Member of the Hong Kong Institution of Engineering (HKIE), founding Council Member of the Supply Chain Council—Greater China, and Chairman of Manufacturing and Industrial Engineering (MIE) Division of the HKIE. He also chairs Advisory Panel of the MIE Discipline of the HKIE, Certification Advisory Council of the British Standard Institute-Pacific, and ES Mark Certification Board.

Dr. Lo is Chartered Engineer, Chartered Member of the Institute of Logistics and Transport, and Fellow of the HKIE. 